\title{
Integrated Approach to the Design of Ballasted Track Substructure using Advanced Computing Techniques
}

\author{
H.-M. Chen, C. Ulianov and R.E. Shaltout
}

NewRail Centre for Railway Research
Newcastle University, United Kingdom

\begin{abstract}
This paper presents an integrated approach to the design of novel track solutions, particularly from the geotechnical perspective, by employing advanced computing techniques capable of establishing design specifications and to optimise the railway track design for light, conventional and heavy freight tracks. The approach uses suitable computing tools for defining and analysing the substructure models and their interfaces, which can then be coupled with the railway superstructure model to analyse the whole vehicle-track interaction and dynamic response. Numerical modelling of the different track design models has been conducted, with comprehensive design considerations and novel reinforcement approaches. The geotechnical material nonlinearity was applied by using the Mohr-Coulomb criteria implemented in finite element analyses. The numerical results show considerable variation of key parameters such as the axle load, and the ballast and sub-ballast layer thicknesses largely affecting the track behaviour. An example case study is further summarised. A comparison has been made between different design solutions for the track substructure. Reasons for the variations in the pressure and displacement distribution patterns have been analysed and discussed, and the selection of the final suitable design for specific subgrade conditions is presented together with appropriate justification.
\end{abstract}

Keywords: track substructure, track design, track stiffness, numerical modelling, finite element, optimisation techniques

\section{Introduction}

Tracks are generally designed and built with a large reserve in order to avoid a possible failure during operation, or to meet new operational needs in the future. However, most track structures are still based on experiences and empirical relations instead of fundamental analyses of track behaviour using numerical simulation and optimisation techniques. 
The railway track substructure is a vital and essential part of the railway track system. The substructure supports the track and is equally as important as the superstructure in ensuring a safe and comfortable ride for freight or passenger trains.

Burrow et al. [1] proposed four railway foundation design procedures and compared the thickness of trackbed layers of each for a number of hypothetical situations. However, the research showed that the procedures did not give consistent results. Further considerations of other aspects were suggested in any new build, renewal or remediation scheme. Nelder et al. [2] introduced a number of design methods to design a new heavy haul freight railway trackbed, founded on moisture sensitive subgrades. Similarly, the results showed considerable variation of thicknesses from each method with little consistent pattern to the variation. In recent years, a number of finite element methods have been proposed, e.g., Chang et al. [3], and Rose et al. [4]. Although there have been developments and successes in providing a universal agreement for modelling the behaviour of the track superstructure, no agreement has been made for the substructure. Insufficient knowledge of non-linear and dynamic characteristics of the ballast, sub-ballast and subgrade materials has been the major reason for the lack of a suitable model of the substructure [5].

Track stiffness is a function of the structural properties of the track superstructure and substructure (ballast and sub-ballast layers). The stiffness and, particularly, the rate of change of stiffness have a strong influence on track behaviour and degradation and play a major role in the design of a new track solution. To account for this effectively, the track design, especially the substructure design, needs to fill some important knowledge gaps in related sciences. An optimised substructure design will determine a high quality of track stiffness and better life cycle performance of the track. $[6,7]$

In this paper, the numerical modelling of the track structure is developed to better understand the mechanical behaviour of the track and the interaction between the track substructure and superstructure components at the rail-wheel contact interface. The railway track substructure considers the ballast, sub-ballast and subgrade, and is defined as the portion of the track structure that lies below and supports the superstructure, which consists of the rail, connectors and sleepers. The railway track is modelled as a multi-layered system based on the stiffness of each layer from the bottom (natural ground) to the top (sleeper and rail). The applied loads on the track substructure are defined taking into account the dynamic load and its impact on train performance.

\section{Railway track design methodology}

For a long time the design of railway tracks has been a matter of learning from past experiences. New insights and techniques are now able to change this manner of working into a more sophisticated approach, which allows a balanced and even optimum track design to be achieved. The variety of track structures is very great as 
the field situations are rather different [8], namely:

- Different axle loads

- Different operating speeds

- Tracks on bridges, in tunnels or in another way integrated in major engineering structures
- Curved and straight lines

- Tracks in transitions

- Tracks in level crossings

- Tracks on specific types of soil

- Urban and rural areas

The primary considerations of track design are safety, economy, ease of maintenance, ride comfort, and constructability. Factors that affect the track system such as safety, ride comfort, design speed, noise and vibration, and other factors such as constructability, maintainability, reliability and track component standardisation, which have major impacts on capital and maintenance costs, must be recognised and implemented in the early phase of planning and design. The objective and responsibility of the designer shall be to design a functional track system that meets current and future needs with a high degree of reliability, and minimal requirements for maintenance and construction, with minimal impact to normal revenue operations.

In particular, a railway track substructure should be stressed well below the limits of its bearing capacity to prevent excessive track settlement. The proposed design approach aims to analyse the deformation behaviour of the substructure under axle load, compare and optimise the track substructure design by varying the properties of each component of the track structure.

The main objective is to identify the optimum design solutions for each of the substructure layers, according to the operating and loading conditions on the track. The design procedure comprises the identification and selection of possible track layers, calculation and/or identification of their mechanical and geometrical properties, according to the applied loads and operational conditions, and, finally, the optimisation of the thickness and composition of each layer, through additional calculations and modifications that can be applied.

\subsection{Track design definitions and specifications}

Only ballasted tracks were considered in this study. Appropriate drainage system is assumed throughout the study, especially for numerical modelling. Figure 1 illustrates the schematic cross section of a typical rail track. The terminology relating to substructure and superstructure used in this paper is based on the standard definitions, as provided by the UIC 719 leaflet [9], except that ballast was considered part of substructure in this paper.

The track structure consists of subgrade, sub-ballast, ballast, sleepers, rail, fastening system, other track materials, special track work, and other elements for signals. Most of the components of the track are briefly defined below.

\section{- Earthworks}

A general term applying to cuttings, embankments, and composite cross sections. 


\section{- Subgrade or platform}

The subgrade is the upper part of the earthworks, on which the blanket layer rests. The platform is the upper surface of the subgrade. The subgrade supports the railway loads transmitted through the rails, sleepers, ballast, and subballast. The subgrade should have adequate width for walkways and a positive slope to either side of the track to keep the subgrade free of standing water. The designer should analyse the existing subgrade and determine whether the material is considered suitable for the subgrade. If the existing subgrade is unsuitable, it should be removed and replaced with approved backfill and shall be compacted in accordance with standard specifications.

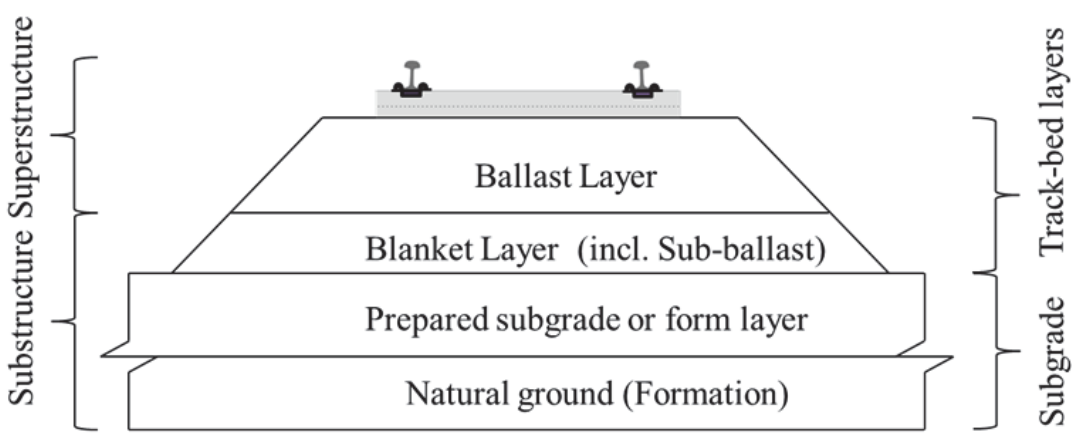

Figure 1: Schematic cross section of rail track

- Blanket layer

The blanket layer lies between the subgrade and ballast. It may include granular, cement or lime treated layers, bituminous layers, geosynthetics or frost isolation plates. It may consist of one or several layers:

- Sub-ballast layer

- Additional blanket layer

- Frost protection layer

- Filtering layer

- Prepared subgrade or form layer

The upper part of the subgrade is formed into a prepared subgrade layer, which normally has a crossfall.

- Track-bed layers

The general term 'track-bed layers' refers to both the ballast and sub-ballast layers.

\section{- Sub-ballast}

Sub-ballast is a uniform layer of approved backfill placed and compacted over the entire width of the subgrade. Sub-ballast should always be considered when the subgrade has poor drainage, of poor material, or is subject to seasonal high water table. The sub-ballast for all tracks should consist of a uniform 
minimum $150 \mathrm{~mm}$ layer of base material. Where the subgrade is soft or with relatively poor drainage, the sub-ballast shall be increased to $300 \mathrm{~mm}$ over geofabric, or if necessary, shall consist of at least $200 \mathrm{~mm}$ thick hot mix asphalt concrete (HMAC) over geotextile fabric $[8,9]$.

\section{- Ballast}

Ballast is placed above the sub-ballast, or HMAC. The ballast plays a critical role by providing support for the rail and sleepers, distributing railroad loads uniformly through the sub-ballast over the subgrade, maintaining proper track alignment, and facilitating track maintenance. Ballast should be crushed rock of acceptable parent material, conforming to Standard Specifications, and shall be obtained from approved quarries.

For the main tracks, including bridges, the minimum ballast depth should be $229 \mathrm{~mm}$, measured from the bottom of the sleepers. Larger ballast section $(300 \mathrm{~mm}$ or more) is commonly used on freight lines. Maximum ballast depth should generally not exceed $457 \mathrm{~mm}$. Ballast depth outside these limits must be approved by relative authorities. Thicker ballast sections resulting in settlement from ballast consolidation increases the maintenance costs due to increased frequency or need for track surfacing [10].

The track superstructure components that should be considered for the track structural design include: rails, under rail pads, fastening systems, sleepers and under sleeper pads in this paper.

The definition of the dynamic properties of the track superstructure components is crucial in the analysis of the vehicle-track dynamics. The simplicity of the models describing vehicle track interactions is lost when the rail is considered as having discrete supports and when non-linearities are associated with the properties of wheelrail contact models, rail pads, and fastening elements. The complications in dynamic models can be generated from the complex geometry of the vehicle and track components including: wheels and rails, the non-linearities in the calculation of the contact forces in the interface between the wheel and rail surfaces, and the number of degrees of freedom of the whole system [11].

\subsection{Track design levels}

There are three design levels which can be adapted for overall track design including substructure and superstructure components, namely [12]:

\section{1) Routine design:}

a) Using linear elastic layer analysis or beam on elastic foundation theory.

b) Simulating the static condition and analysis of loading cycles and scenarios.

\section{2) Advanced design:}

a) Using a two- and three-dimensional finite element method (FEM) or finite difference method (FDM) based programs, or hybrid methods (Coupled FEM 
and multi-layer systems e.g. the ground layer through discrete Green's functions).

b) Multibody simulation package may be introduced to perform the dynamic analysis of the railway vehicles running on the proposed track with the designed loading scenarios with different running conditions.

\section{3) Research based design:}

a) Three-dimensional FEM, FDM, or distinct element method (DEM) based programs.

b) Including the track flexibility in the dynamic interaction problem between the vehicle and the track.

c) Integration of dynamic analysis outcomes, such as advanced contact models to precisely define the local mechanical behaviour of contact points, and forces at each contact patch to determine the suitable wear and rolling contact fatigue criteria.

This study investigated both routine and advanced design approaches using a numerical modelling technique for the railway substructure. An integrated approach was developed in order to analyse the railway track substructure performance for light, conventional and heavy traffic freight lines.

\section{Case study: a heavy freight line}

The design procedure and focus was on the advanced numerical modelling and simulation of track substructure for determining key parameters to be further used as key criteria for the substructure design. The design procedure has been tested and applied for the design of both urban and freight lines, and comprised the following:

1. Numerical modelling of the different track design models for each case study has been conducted, with comprehensive design considerations and novel reinforcement approaches. The geotechnical material nonlinearity was applied by using the Mohr-Coulomb criteria implemented in finite element analysis (FEA).

2. A comparison has been made between different design solutions for the track substructure. The numerical results showed considerable variation of key parameters such as the axle load, and the ballast and sub-ballast layer thicknesses, and track stiffness largely affecting the track mechanical behaviour. Reasons for the variations in the pressure and displacement distribution patterns have been analysed and discussed.

3. The selection of the final suitable design for specific subgrade conditions was made with respect to the analysis outcomes and appropriate justification.

In this paper, a specific case study of track design for a new railway track that has to be suitable for heavy freight traffic conditions is presented. The substructure layers 
were defined including a special geological condition. It is based on rigid rock; thus a subgrade layer is not considered here.

Several steps were followed to develop optimal track structures under various predefined conditions. The mechanical behaviour of a track has been analysed using two-dimensional finite element models wherein the track and moving train have been incorporated. To obtain the optimum design, component dimensions and mechanical properties of the track model were varied. Finally, optimal track parameters are determined by applying a numerical optimisation technique. The results of the optimisation are presented and discussed in the following sections. The static loading scenarios were initially addressed in the research. However, the dynamic effect of the running train on the loading conditions was taken into account through a dynamic impact factor in the calculation of the applied loads.

Finally, the optimised superstructure solutions were integrated into the optimised track design and the dynamic behaviour was analysed with respect to the track-vehicle interaction. The impacts of the changes implemented into the new track design were assessed through dynamic modelling for validating the solution in simulated operational conditions.

\subsection{Railway track structure design}

One of the most essential design steps is to determine ballast surface stress, calculate track deflection under load and check on acceptability. If deflection is unacceptable, the design has to be re-done. The next step after the analysis of the railway track structural behaviour is its optimisation by modifying separate design parameters and performing repeated numerical analyses.

\subsubsection{Railway track superstructure}

The definition of the specifications of track superstructure components has a great influence on the optimisation of the design of ballasted tracks through numerical simulations. Various modifications of geometric and dynamic properties of track superstructure components have been performed. The main objective was to determine the impact of these properties on the dynamic behaviour of the track system and the reduction of the global stiffness of the track. The main parameters that could be considered for the superstructure components include the following:

- Rail parameters - the following rail parameters are considered in the design process:

1) Rail steel properties

These properties include the definition of the steel grades and the rail hardness values. The criteria used for the definition of the steel grades are related to parameters that influence the development of wear and rolling contact fatigue. Hardness and its distribution through the railhead depth govern wear resistance, 
and plastic flow of the railhead. It is also important for resistance to the initiation of rolling contact fatigue.

2) Rail section and profiles

Rail profiles are crucial in the modelling of vehicle-track dynamic interactions. The contact problem has a great influence on the vehicle dynamics because all the forces resulting from the interaction with the vehicle are transmitted through the contact forces. The wheel-rail interaction phenomenon involves the definition of the contact bodies (detection of the contact areas between the wheel and the rail and definition of the shape and size of the contact area), so it is necessary to precisely define the profiles of the wheel as well as the rail, as two bodies in contact.

\section{- Under rail pads (URP)}

For low frequencies, the vehicle dynamics influence is strong and so is not the URP stiffness influence. For higher frequencies, there is a strong influence of the URP stiffness through the resonance of the unsprung mass on the track. Modification of the rail pad stiffness shows that the lower the pad stiffness, the lower the vehicle-track resonance frequency.

\section{- Fastening systems}

The purpose of the rail fastenings is to maintain the track gauge and transmit the forces acting on and in the rails to the sleeper. The properties of the fastening system have to be considered when the rails are subjected to vertical movements under heavy loads. The forces acting on the fastening system are vertical, lateral, rotational (both planes) and longitudinal, and are the result of repeated loading cycles from passing axles, as well as longitudinal stresses in the rail. One way to objectively compare fastening systems is to analyse the elasticity of each system. The elasticity of a fastening system refers to the amount of rail movement allowed within the rail seat area, or the "working range" of the fastening system.

\section{- Sleepers}

Sleeper manufacturers have developed solutions which would be compatible with different axle-loads applications. Different sleeper solutions include both rigid models and types that take into account the flexibility in lateral and longitudinal directions. The sleeper mass and length influence the track receptance. The sleeper mass also influences the resonance of the sleeper (and of the rails) on the ballast.

\section{- Under sleeper pads (USP)}

Under sleeper pads are beneficial for the sleeper-ballast interface. The area of contact is increased significantly, reducing the pressure between the ballast and the sleepers, and thus reducing the deterioration rate of both sleepers and ballast. This adds flexibility to the sleeper dimensions and the footprint required to carry the loads applied to the sleepers. The pads also provide additional resistance to sleeper transverse and longitudinal movement. Nevertheless, low USP stiffness leads to high track deflection. 
Table 1 summarises the dynamic properties of the track, which were considered by this research. The values of the parameters defined in the table have been modified according to various solutions in the design process of the track superstructure, as well as substructure components.

\begin{tabular}{|c|c|}
\hline Parameter & Remarks \\
\hline Trackbed Vertical Stiffness [kN/mm] & \multirow{2}{*}{$\begin{array}{l}\text { Extracted from the FE model } \\
\text { of the track substructure }\end{array}$} \\
\hline Trackbed Vertical Damping [kNs/m] & \\
\hline Under Rail Pad Stiffness [kN/mm] & \multirow{4}{*}{$\begin{array}{l}\text { Defined by the user depending } \\
\text { on Tonnage carried; Speed and } \\
\text { cant of curves; Axle load; } \\
\text { Type of rolling stock. }\end{array}$} \\
\hline Under Rail Pad Damping coefficient [kNs/m] & \\
\hline Under Sleeper Pad Stiffness [kN/mm] & \\
\hline $\begin{array}{l}\text { Under Sleeper Pad Damping coefficient } \\
{[\mathrm{kNs} / \mathrm{m}]}\end{array}$ & \\
\hline
\end{tabular}

Table 1: Dynamic properties of the track system

\subsubsection{Railway track substructure}

Considering the specific conditions of the analysed route, the primary selection of technologies and track solutions, varying the ballast layer thickness, blanket layer layout and loading conditions for the new track, has been summarised in Table 2 and further detailed.

\begin{tabular}{|c|c|c|c|c|c|}
\hline \multirow{2}{*}{ No. } & \multirow{2}{*}{$\begin{array}{c}\text { Short } \\
\text { Name }\end{array}$} & $\begin{array}{c}\text { Ballast } \\
\text { Layer } \\
\text { Thickness } \\
(\mathbf{m m})\end{array}$ & $\begin{array}{c}\text { Sub- } \\
\text { ballast } \\
\text { Layer } \\
\text { Thickness } \\
(\mathbf{m m})\end{array}$ & $\begin{array}{c}\text { Asphalt } \\
\text { Concrete } \\
\text { Layer } \\
\text { Thickness } \\
(\mathbf{m m})\end{array}$ & $\begin{array}{c}\text { Equivalent } \\
\text { Dynamic } \\
\text { Loading } \\
(\boldsymbol{k N} / \text { wheel })\end{array}$ \\
\hline 1 & CT 300 & 300 & - & - & $63[22.5$ t/axle] \\
\hline 2 & HH 300 & 300 & - & - & $112[40$ t/axle] \\
\hline 3 & HH 400 & 400 & - & - & $112[40$ t/axle] \\
\hline 4 & HH 500 & 500 & - & - & $112[40$ t/axle] \\
\hline 5 & HH 300S & 300 & 300 & - & $112[40$ t/axle] \\
\hline 6 & HH 300S+ & 300 & 200 & - & $112[40$ t/axle] \\
\hline 7 & HH 300A & 300 & - & 50 & $112[40$ t/axle] \\
\hline 8 & HH 300A+ & 300 & - & 200 & $112[40$ t/axle] \\
\hline
\end{tabular}

Table 2: Selected substructure solutions for heavy traffic freight track design

- Substructure Solution 1: conventional track design with only a ballast layer of minimum thickness $h_{b}=300 \mathrm{~mm}$ and rock formation for freight line under standard load (22.5 t/axle load) - to be used as general freight benchmark solution, as shown 
in Figure 2 a);

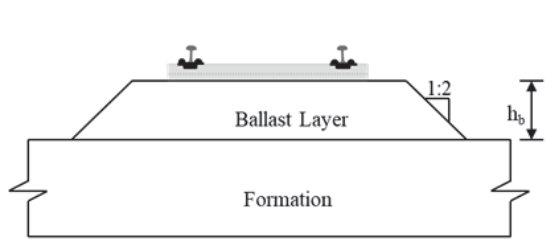

a)

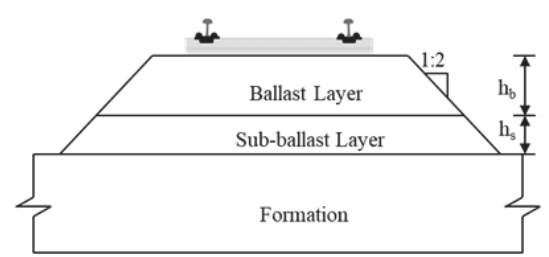

b)

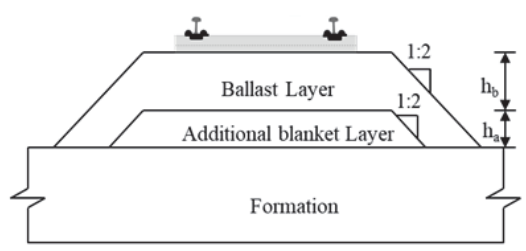

c)

Figure 2: Track substructure designs

a) solutions $1-4$; b) solutions $5-6$; c) solutions $7-8$

- Substructure Solutions 2, 3 and 4: conventional freight track designs including a ballast layer varying from 300,400 to $500 \mathrm{~mm}$, and rock formation under increased axle load (40 t/axle load) - to be used as a comparison to the general freight benchmark solution in heavy freight lines, as shown in Figure 2 a);

- Substructure Solutions 5 and 6: improved freight track designs under increased axle (40 t/axle load) with minimum standard ballast layer of $300 \mathrm{~mm}$ and subballast layer of a varied thickness ( $h_{s}=200$ and $h_{s}=300 \mathrm{~mm}$, respectively), as shown in Figure 2 b);

- Substructure Solutions 7 and 8: improved freight track designs under increased axle load (40 t/axle load) with minimum standard ballast layer of $300 \mathrm{~mm}$ and Asphalt Concrete (AC) layer as an additional blanket layer of a varied thickness $\left(h_{a}=50\right.$ and $h_{a}=200 \mathrm{~mm}$, respectively), as shown in Figure $2 \mathrm{c}$ ).

\subsection{Numerical simulation using advanced computing tools}

The analysis employed advanced computing techniques capable of establishing top design criteria and design specifications for light, main and heavy freight tracks. The proposed approach uses advanced numerical modelling techniques for track analysis, and subsequent suitable computing tools for defining and analysing the substructure models and their interfaces and dependencies with the superstructure.

\subsubsection{Numerical methods and tools}

The FEM and the FDM are widely used for numerical modelling and analysing the general behaviour of track components in certain conditions. In addition, the DEM is 
used to describe the local mechanical behaviour of discontinuous bodies such as unbound ballast. Currently, the design methods treat the ballast as a continuous medium. Thus, both the FEM and the FDM are feasible to simulate the ballast section performance. Specific programs based on the FEM can be used to perform very detailed analyses of displacements, stresses and strains of track components. Therefore, the analysis of the 2D model was performed using the general-purpose FE package 'PLAXIS' in this study.

Various computational packages are being used in the dynamic analysis of the vehicle - track interaction. Most of these packages use the multibody methodology in the analysis of the vehicle dynamics, as well as the track performance. Generally, all these computational tools share the same functionality and basic foundations for predicting or analysing the performance of railway vehicles in different operation scenarios. The theoretical basis of the mathematical modelling is mature and reliable in most of the simulation tools. The most powerful packages used for railway dynamic analysis include: SIMPACK, VAMPIRE, GENSYS, NUCARS, ADAMS/Rail and UNIVERSAL MECHANISM. The vehicle model used in the simulation purpose in the presented research was modelled using the multi-body system formulation implemented in the VAMPIRE commercial simulation tool.

\subsubsection{Numerical modelling configuration}

In order to reduce the complexity of the track design, only the vertical wheel load is considered in the numerical model. The first two steps in studying the behaviour are schematising the structure and collecting the necessary parameter data from field or laboratory experiments. Some of the parameters can be achieved by performing widely applied testing methods for track structures. They are therefore described in international standards.

\section{1) Geometrical parameters of the model}

The cross section of a single-line ballasted track was modelled in 2D by using the FEM. Although the wheel-induced stresses primarily decreased after the depth of approximately $2 \mathrm{~B}$ (with $\mathrm{B}$ as length of sleeper) beneath the track bed, for assurance, the depth of subgrade is supposed to be $15 \mathrm{~m}$ in the model. Due to the symmetrical geometry of the track section, only half of the track section has been considered in the modelling procedure. All the models are in the transverse direction against the rail track.

\section{2) Materials selection}

- Ballast: Granite aggregates;

- Sub-ballast: Crushed stone;

- Rock base: Granite.

\section{3) Mechanical properties of the track and substructure}

The primary purpose of the study was to comprehensively investigate the ballast and sub-ballast elasto-plastic behaviour effects on the track performance and 
pressure on the sleeper. Hence, the rail and sleeper materials were assumed to be elastic and other materials are considered elasto-plastic using the Mohr-Coulomb criteria. Table 3 summarises the critical parameters and properties of the track components that were used in the modelling.

\begin{tabular}{|c|c|c|}
\hline Element & Parameter & Value \\
\hline \multirow[t]{2}{*}{ Track } & Total Length & $15.12 \mathrm{~m}$ \\
\hline & Dimensions $(\mathrm{H} \times \mathrm{W})$ & $0.172 \times 0.15 \mathrm{~m}$ \\
\hline \multirow[t]{4}{*}{ Rail (60 E1) } & Area & $76.84 \mathrm{~cm}^{2}$ \\
\hline & Density & $7800 \mathrm{~kg} / \mathrm{m}^{3}$ \\
\hline & Young's Modulus & $210 \mathrm{GPa}$ \\
\hline & Poisson's Ratio & 0.3 \\
\hline \multirow[t]{6}{*}{ Sleeper } & Spacing & $0.63 \mathrm{~m}$ \\
\hline & Young's Modulus & $26 \mathrm{Gpa}$ \\
\hline & Poisson's Ratio & 0.15 \\
\hline & Ydry & $24 \mathrm{kN} / \mathrm{m}^{3}$ \\
\hline & Ywet & $24 \mathrm{kN} / \mathrm{m}^{3}$ \\
\hline & Dimensions $(\mathrm{L} \times \mathrm{H} \times \mathrm{W})$ & $2.5 \times 0.22 \times 0.28 \mathrm{~m}$ \\
\hline \multirow[t]{5}{*}{ Ballast } & Young's Modulus & $390 \mathrm{Mpa}$ \\
\hline & Poisson's Ratio & 0.4 \\
\hline & Ydry & $18 \mathrm{kN} / \mathrm{m}^{3}$ \\
\hline & Jwet & $20 \mathrm{kN} / \mathrm{m}^{3}$ \\
\hline & Friction Angle & $35^{\circ}$ \\
\hline \multirow[t]{5}{*}{ Sub-ballast } & Young's Modulus & $81 \mathrm{Mpa}$ \\
\hline & Poisson's Ratio & 0.35 \\
\hline & Ydry & $17 \mathrm{kN} / \mathrm{m}^{3}$ \\
\hline & Ywet & $20 \mathrm{kN} / \mathrm{m}^{3}$ \\
\hline & Friction Angle & $30^{\circ}$ \\
\hline \multirow[t]{4}{*}{ AC layer } & Ydry & $25 \mathrm{kN} / \mathrm{m}^{3}$ \\
\hline & Jwet & $25 \mathrm{kN} / \mathrm{m}^{3}$ \\
\hline & Young's Modulus & $5.4 \mathrm{Gpa}$ \\
\hline & Poisson's Ratio & 0.3 \\
\hline \multirow[t]{6}{*}{ Rockbed } & Young's Modulus & $73.8 \mathrm{Gpa}$ \\
\hline & Poisson's Ratio & 0.22 \\
\hline & Ydry & $27 \mathrm{kN} / \mathrm{m}^{3}$ \\
\hline & Jwet & $27 \mathrm{kN} / \mathrm{m}^{3}$ \\
\hline & Friction Angle & $51^{\circ}$ \\
\hline & Cohesion & $55.1 \mathrm{Mpa}$ \\
\hline
\end{tabular}

Table 3: Geometry and material parameters for new track design [13-16]

\section{4) Loading conditions}

Concerning the traffic loading on the new track, two different types of trains were considered. These were representative of conditions on a standard rail train with 
loads of 22.5 tonnes per axle, and a heavy freight train with an axle-load of 40 tonnes, running at $60-80 \mathrm{~km} / \mathrm{h}$.

- Benchmark static load for standard rail train: $22.5 \mathrm{t} / \mathrm{axle}=112.5 \mathrm{kN} /$ wheel applied to the rail, or

- Static load for heavy freight train: $40 \mathrm{t} / \mathrm{axle}=200 \mathrm{kN} /$ wheel applied to the rail

Modelling and simulation in the field of railway dynamics is a complex interdisciplinary topic. At the first stage an equivalent dynamic wheel load was used as the wheel loading condition in the modelling for simplicity. Loads at the wheel-rail interface produced by moving loads are greater than those produced by the same wheel loads at rest [17]. Typically, the design wheel load is higher than the static wheel load to account for this increase due to speed, i.e.

$$
P_{d}=\varnothing P_{S}
$$

where, $P_{d}$-- dynamic wheel load; $\phi$ - dynamic wheel load factor; $P S$ - static wheel load.

The dynamic wheel load factor is typically developed empirically using field data and is expressed in terms of train speed. An equivalent dynamic wheel load $\left(P_{d}\right)$ for a given static wheel load $\left(P_{\mathrm{s}}\right)$ using the Talbot dynamic factor incorporates wheel diameter and is calculated as by the American Railway Engineering Association [18]:

$$
\varnothing=1+\frac{0.0052 \mathrm{~V}}{D}
$$

where, $V$ is the train speed $(\mathrm{km} / \mathrm{h}), D$ the wheel diameter $(\mathrm{m})$.

The average speed of the specific freight train was considered to be $70 \mathrm{~km} / \mathrm{h}$, and the wheel diameter is $0.915 \mathrm{~m}$. Then, the calculated dynamic impact factor is 1.4. According to the load distribution in the figure below, the equivalent dynamic wheel load is:

- Standard loading of freight train (22.5 t/axle): $P_{d}=63 \mathrm{kN} /$ wheel applied to the sleeper just below the wheel

- Heavy freight train loading (40 t/axle): $P_{d}=112 \mathrm{kN} /$ wheel applied to the sleeper just below the wheel.

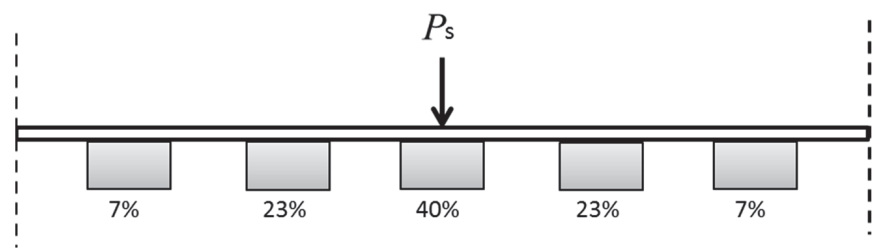

Figure 3: Distribution of axle load to the sleepers [19] 


\subsubsection{Numerical simulation results}

The total depth of the specific rock formation base was set to be $15 \mathrm{~m}$ in the models. The following figures only show the upper $1.6 \mathrm{~m}$ section, presenting the vertical stress and horizontal displacement distribution of some designs.

Examples of vertical stress distribution are presented in Figures 4 to 7. Examples of total horizontal displacement distribution are presented in Figures 8 to 10.

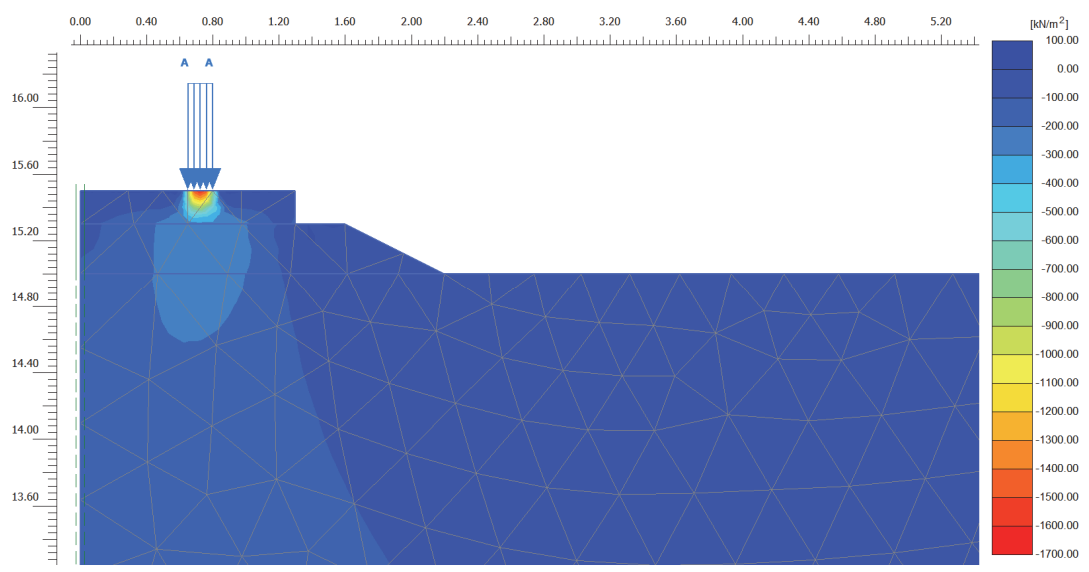

Figure 4: Cartesian effective stress $\boldsymbol{\sigma}_{\mathrm{yy}}$ distribution for CT 300

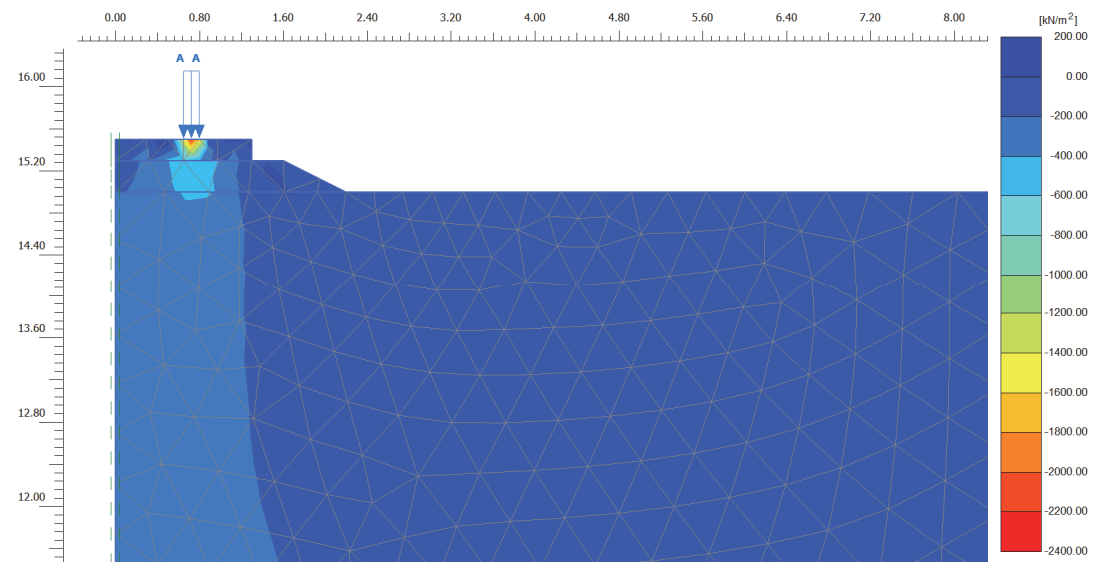

Figure 5: Cartesian effective stress $\boldsymbol{\sigma}_{\mathrm{yy}}$ distribution for $\mathrm{HH} 300$ 


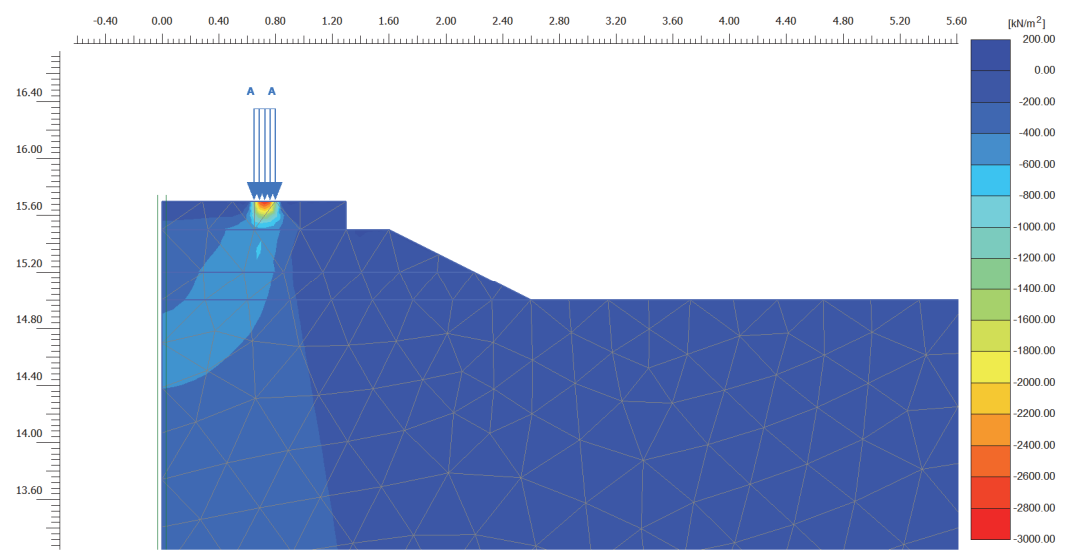

Figure 6: Cartesian effective stress $\grave{\sigma}_{\mathrm{yy}}$ distribution for HH $300 \mathrm{~S}+$

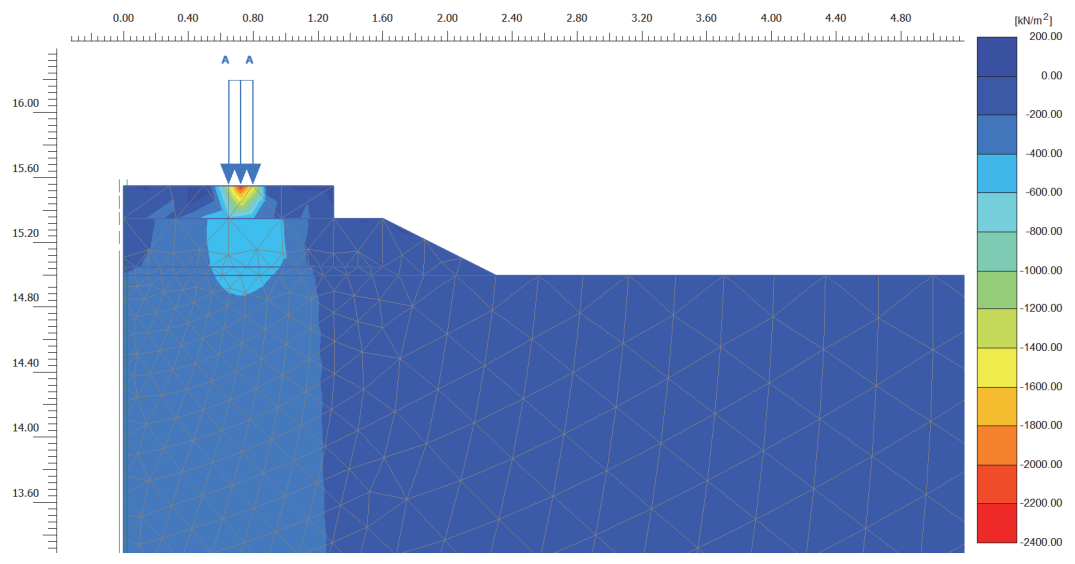

Figure 7: Cartesian effective stress $\boldsymbol{\sigma}_{\mathrm{yy}}$ distribution for HH 300A

An insufficient depth of ballast overloads the underlying soil; in the worst cases, this can cause the track to sink. If the ballast is less than $300 \mathrm{~mm}$ thick, this can lead to vibrations, which can damage nearby structures (though increasing the depth beyond this has no measurable effect).

However, when increasing ballast thickness from $300 \mathrm{~mm}$ to $500 \mathrm{~mm}$, the structure is more vulnerable to larger horizontal deformations especially in the embankment (ballast layer) as can be compared in Figure 8 to 10. There is an increased risk of embankment instability and failure of the shoulder of the embankment without any ballast reinforcement methods. Therefore, reinforcement of the ballast layer is highly 
recommended, especially solutions like geogrids reinforcement [20] or XiTRACK Technology [21].

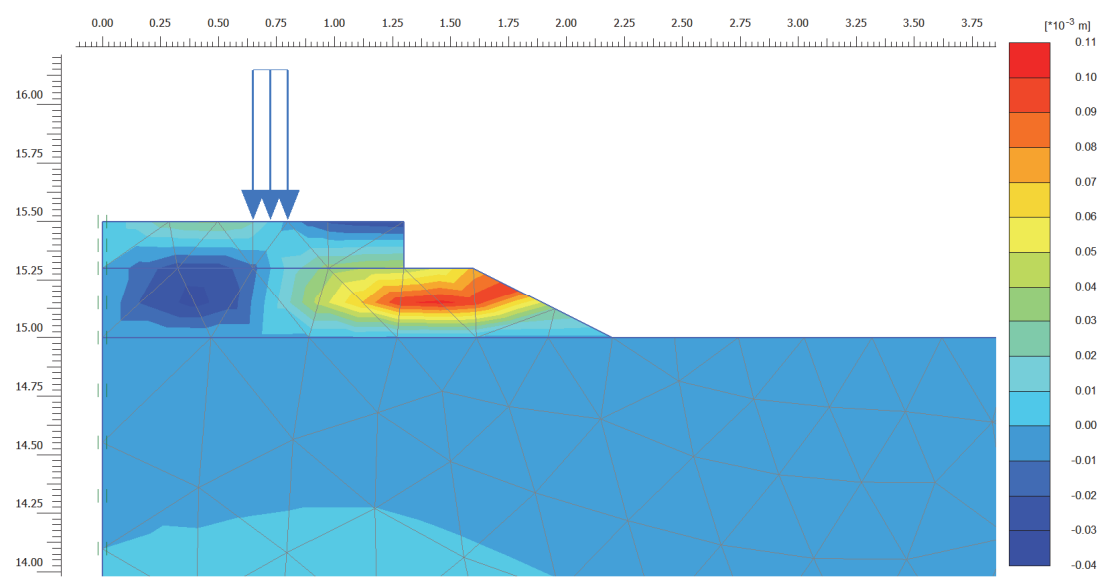

Figure 8: Total horizontal displacements Ux distribution for $\mathrm{HH} 300$

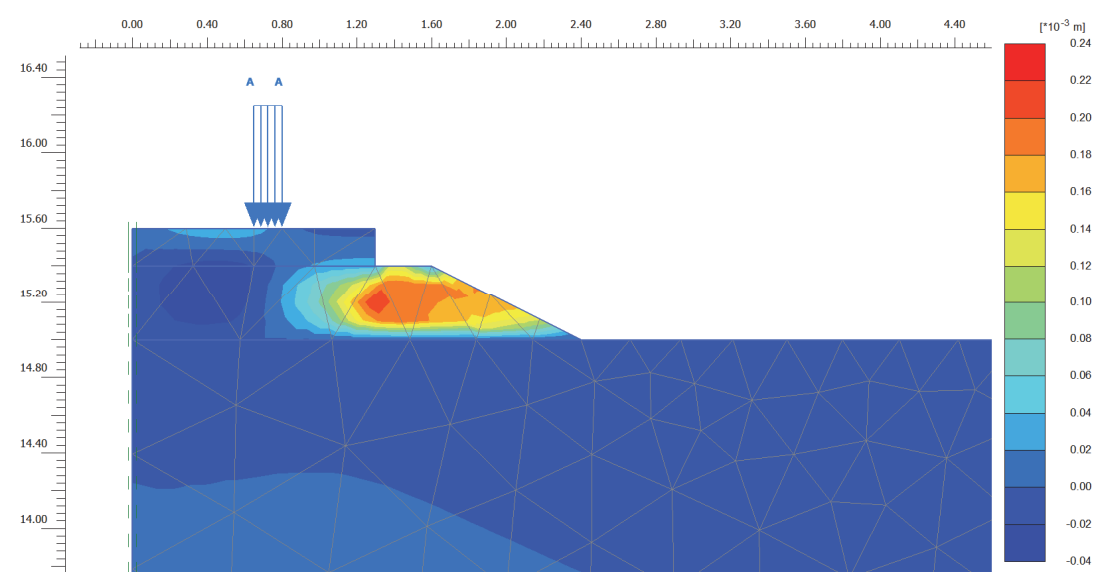

Figure 9: Total horizontal displacements Ux distribution for $\mathrm{HH} 400$

In addition, stress and deformation results of the track substructure are presented with the maximum values for each substructure solution for comparison (for more details refer to $[11,22])$.

A connection has been established between the multibody simulation package, used in the dynamic analysis of the whole vehicle-track system, and the finite element software used in the analysis of the track substructure, as the dynamic simulation of the vehicle-track interaction uses inputs such as track stiffness from the FE modelling 
of the track substructure. Thus, the track dynamic properties have been updated simultaneously to the multibody simulation program for each track section.

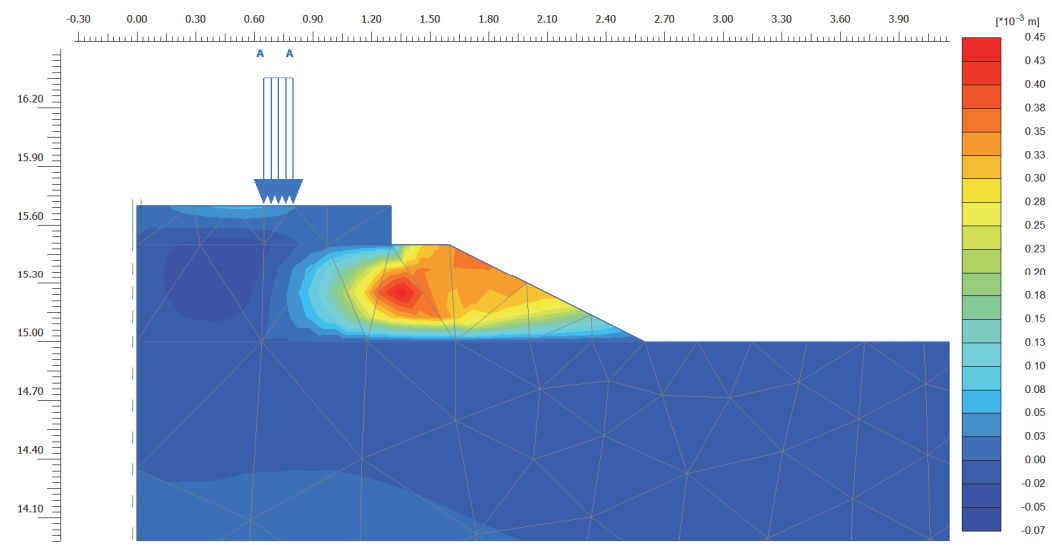

Figure 10: Total horizontal displacements Ux distribution for HH 500

The novel approach was described as "integrated", because the dynamic simulation of the vehicle-track interaction uses inputs such as track stiffness from the FE modelling of the track substructure, rather than estimated values of combined staticdynamic loads (as in the 'traditional' approach for this purpose).

\section{- Example of dynamic modelling results}

1) Analysis of the track stiffness impact

The vehicle track interaction model used in the simulation has been used to determine the influence of track stiffness on track response by comparing various designs. A comparison was made between two track models with different stiffness.

The first track type (T1) has a vertical stiffness of $270 \mathrm{kN} / \mathrm{mm}$, and the second one (T2) is stiffer, with a vertical stiffness of $400 \mathrm{kN} / \mathrm{mm}$. An example of simulation outcomes for both tracks is presented in Figure 11, showing the comparison between the results for both track T1 and T2, for the left rail lateral displacement under the leading wheelset of the vehicle moving with a speed of $80 \mathrm{~km} / \mathrm{h}$.

2) Analysis of the speed impact

The influence of the running speed on the dynamic vehicle-track interaction was analysed by comparing the simulation results for the scenarios with running speeds of $60 \mathrm{~km} / \mathrm{h}$, with respect to $80 \mathrm{~km} / \mathrm{h}$. The comparison of the results demonstrates a significant effect of the vehicle speed on the dynamic interaction with the track. 
Figure 12 depicts the lateral displacement of the sleeper under the moving train with different operational speeds. It can be noted that the displacement increases with the increase in the running speed.

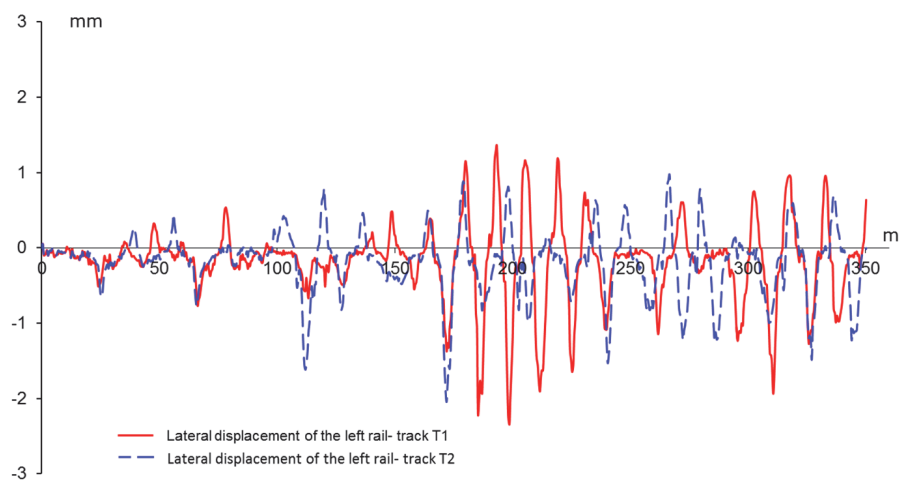

Figure 11: Lateral displacement of the left rail under leading wheelset

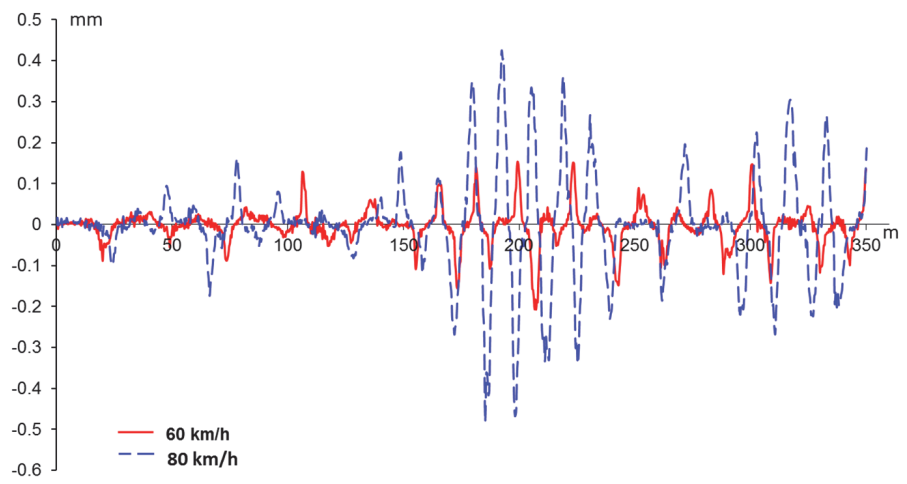

Figure 12: Lateral displacement of the sleeper under the leading wheelset

\subsubsection{Analysis and discussion of results}

In order to get a better understanding and comparable results of substructure designs, the following characteristics of various track substructure designs are compared with each other:

1) Sleeper surface pressure and displacement;

2) Ballast surface pressure and displacement;

3) Formation surface displacement.

\section{- Sleeper results}

Figures 13 and 14 show that in the case of sub-ballast layer, the structure is more vulnerable to larger deformations concentrated in the sleeper, ballast and sub- 
ballast layer with risk of embankment reduced stability and failure of the shoulder of the embankment.

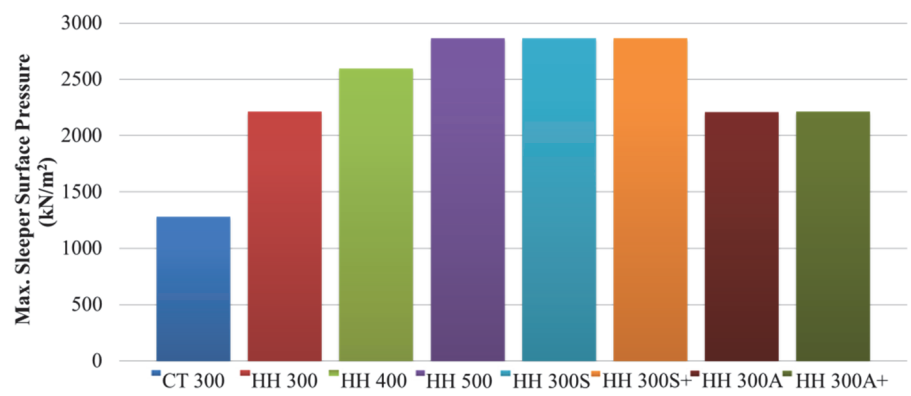

Figure 13: Maximum sleeper surface pressure for analysed substructure solutions

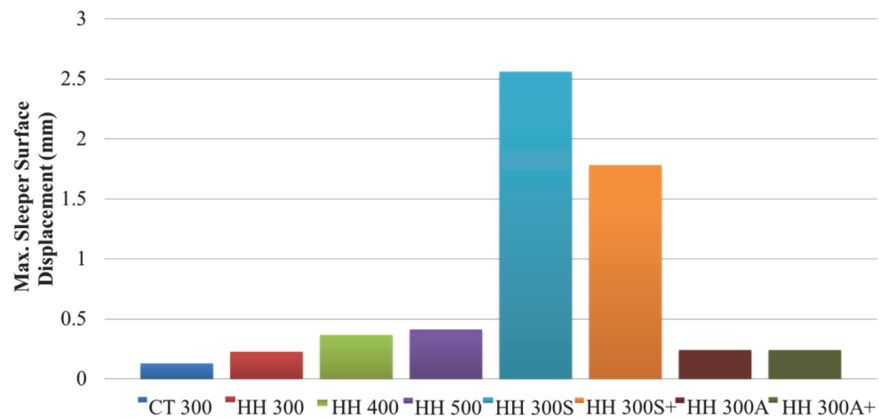

Figure 14: Maximum sleeper surface displacement for analysed substructure solutions

\section{- Ballast results}

Similarly, Figure 15 shows that the presence of sub-ballast layer not only largely increases the track deformation from rail, sleeper, ballast to sub-ballast layer, but also enlarges the loading pressure transmitted to the lower substructure.

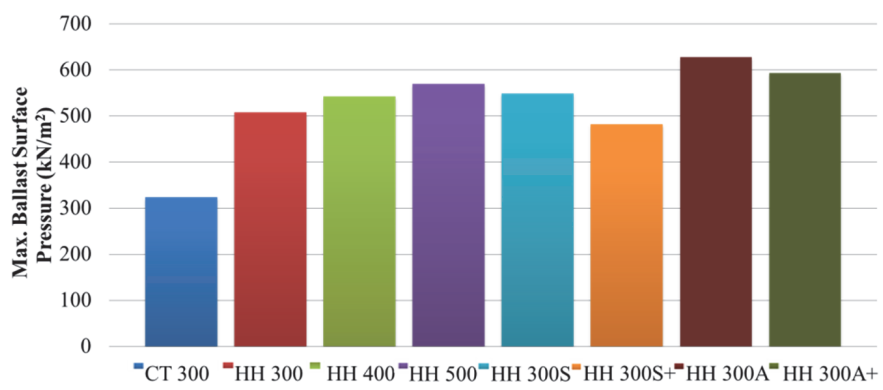

Figure 15: Maximum ballast surface pressure for analysed substructure solutions 
Both the sleeper (Figure 14) and the ballast results (Figure 16) show that the subballast layer increases significantly the track displacement, which indicates that this layer is likely to largely influence the track mechanical behaviour.

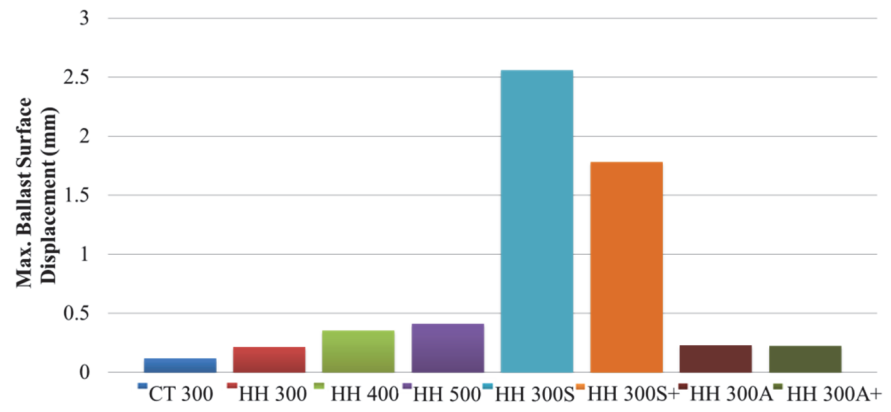

Figure 16: Maximum ballast surface displacement for analysed substructure solutions

\section{- Rock base results}

Due to the high stiffness of the rock base, very low displacement, within $0.03 \mathrm{~mm}$, is obtained in the numerical modelling. All the solutions suggest very few variations in the displacement. Thus, it is hard to compare the optimised substructure solutions according to rock base surface displacement.

It should be noted that ballast and sub-ballast are assumed as isotropic continuum media, which is a popular simplified model in the geotechnical numerical simulation. However, it is not equal to the real conditions.

\section{- Effect of sub-ballast and its thickness}

One of the biggest functions of the sub-ballast is to reduce the large vertical stress allowed by the ballast before it reaches the subgrade, especially a softer one. Since this loose material (crushed gravel or sand) is a good energy absorbent, it actually leads to energy dissipation.

However, since ballast and sub-ballast are assumed as isotropic continuum media in the numerical modelling, the results showing higher pressure, i.e. the designs with sub-ballast in Figure 13 and Figure 15, may not accurately describe the real case. The sub-ballast designs present comparably larger displacement than other substructure designs, as it can be seen in Figures 14 and 16, which proves that the sub-ballast designs have reduced the track bed stiffness and result in higher risk of track bed instability and more need for maintenance activities to the ballast layer.

In any case, if sub-ballast were to be used for new track substructure design, it would be suggested to use thinner sub-ballast layers (e.g., $200 \mathrm{~mm}$ thick) rather 
than thicker ones (e.g., $300 \mathrm{~mm}$ thick), as shown in Figure 14 and Figure 16, where the track deforms less with $200 \mathrm{~mm}$ thick sub-ballast layer. In addition, a bi-axial geogrid is typically placed over the non-woven polypropylene geotextile to serve as the geocomposite layer at the bottom of the sub-ballast.

\section{- Effect of AC and its thickness}

The need for less material for an AC layer compared to a conventional granulartype layer (e.g., sub-ballast layer) can also have construction cost and schedule benefits when suitable granular material is not readily available. AC, especially HMAC, is recommended in new track substructure design, especially under heavy axle load trains, in order to achieve an acceptable balance between the effect of the reduction of track deflection and the increase in ballast pressure. Compared to the conventional design (track with only ballast layer and rock base), AC in different thicknesses $(50$ and $200 \mathrm{~mm}$ ) performs well in terms of reducing track deformation, due to its comparatively higher stiffness, as can be seen in Figure 15.

The variation of AC thickness does not show apparent influence on track structure pressure and displacement. Therefore, the thinner AC of $50 \mathrm{~mm}$ thickness, is highly recommended for new track substructure design, considering the economic and life-cycle cost.

- Effect of loading conditions

Clearly the increase of axle load (from 22.5 t/axle to 40 t/axle in solution CT 300 and HH 300 individually, other conditions are kept the same) has a significant effect on the sleeper and ballast performance and this should be considered when programming and operating a variation of traffic conditions on a track.

\section{- Effect of overall track stiffness on dynamic vehicle-track interaction}

The determination of vertical track stiffness is crucial in railway system engineering for both design and maintenance. Global track stiffness is an important parameter in the design of railway tracks that can affect the wheel-rail interaction as well as the track degradation. On the other hand, the local track stiffness depends on the stiffness of the components and layers of the track model. The local stiffness in the presented analysis was determined from the finite element analysis of the substructure track model. The track stiffness has also a major effect on the distribution of the forces on the track elements including rails, rail pads and under sleeper pads, fastenings and sleepers, and the sleeper-ballast interface.

\section{Conclusions}

This paper presents an integrated approach to the design of new track solutions. The design procedure employs advanced computing tools to establish design specifications and to optimise the railway track structure design for light, main and heavy freight tracks. 
State-of-the-art numerical approaches and models have been briefly reviewed. Currently, the design methods treat the ballast and sub-ballast layers as isotropic continuous media. Thus, both FEM and FDM are feasible to simulate the ballast section performance. In the project, the material nonlinearity was applied by using the Mohr-Coulomb criteria implemented in FEA using a commercial code.

A series of substructure design solutions have been selected for a case study of a heavy traffic freight track, with novel technologies by varying the thickness, the reinforcement methods, addition of ballast, blanket layer and loading conditions, followed by numerical modelling to justify the selection of track designs.

Numerically predicted results have been presented and assessed, showing how the variation of key parameters such as the axle load and the thickness of ballast and subballast layer largely affect the track performance. The comparison of analysis results for the various models showed significant differences in the pressure and displacement distribution both in terms of patterns and values.

The numerical results showed that the proposed design procedure and approach using advanced numerical modelling can effectively be used for the design of railway structures, as well as studying the track performance, especially substructure under different loading and design conditions.

\section{References}

[1] M. Burrow, G. Ghataora and H. Evdorides, "Railway Foundation Design Principles", Journal of Civil Engineering and Architecture, 224-232, (3), 2011.

[2] L.M. Nelder, C. England, R.J. Armitage, et al. "A comparison of trackbed design methodologies: a case study from a heavy haul freight railway", CRC press (Taylor \& Francis group), 2008.

[3] C.S. Chang, C.W. Adegoke, E.T. Selig. "The GEOTRACK Model for Railroad Track Performance", Journal of the Geotechnical Engineering Division, ASCE, 106(11) pp1201-1218, 1980.

[4] J.G. Rose, S. Bei and W.B. Long. "Kentrack: A Railway Trackbed Structural Design and Analysis Program", Proceedings of the AREMA Annual Conference, Chicago, 2003.

[5] J. Sadeghi, "Investigation of characteristics and modelling of railway track system", Ph.D. Thesis, School of Civil, Mining, and Environmental Engineering, University of Wollongong, Australia, 1997.

[6] J.A. Zakeri, R. Abbasi, "Field investigation on variation of rail support modulus in ballasted railway tracks", Latin American Journal of Solids \& Structures, 2012, 9(6):643-656.

[7] P.V. Vreden, A.M. Hartman, \& P.J. Grabe, "Characterising railway substructure layers for rehabilitation design", in the 31th Southern African Transport Conference, Vol.59, 2012.

[8] V.L. Markine, A.P. De Man, C. Esveld, "A procedure for design and optimization of a railway track structure", Railway Engineering Group, Civil 
Engineering and Geosciences, Delft University of Technology, 1998.

[9] UIC 719-2008 Earthworks and track bed construction for railway lines.

[10] IHHA ICMI - IHHA Guidelines to Best Practices for Heavy Haul Railway Operations - Infrastructure Construction and Maintenance Issues.

[11] R.E. Shaltout, C. Ulianov, H.-M. Chen, "Coupled Numerical Modelling of Railway Track Substructure with Vehicle-Track Interaction", in J. Kruis, Y. Tsompanakis, B.H.V. Topping, (Editors), "Proceedings of the Fifteenth International Conference on Civil, Structural and Environmental Engineering Computing", Civil-Comp Press, Stirlingshire, UK, Paper 125, 2015. doi:10.4203/ccp.108.125

[12] A.G. Correia, "Soil mechanics in routine and advanced pavement and rail track rational design", Geotechnics for roads, rail tracks and earth structures, 165$187,2001$.

[13] R.E. Goodman, "Introduction to Rock Mechanics", John Wiley \& Sons, New York, 1980.

[14] L.K-. Tanttu, R. Laaksonen, "Modelling of the stress state and deformations of APT tests", in "International Conference on Accelerated Pavement Testing", 2nd, Minneapolis, Minnesota, USA, 2004.

[15] A.G. Correia, J. Cunha, J. Marcelino, L. Caldeira, J. Varandas, Z. Dimitrovová, M. Silva, "Dynamic analysis of rail track for high speed trains. 2D approach", in "5th Intl Worksop on Application of Computational Mechanics on Geotechnical Engineering”, 04, 2007.

[16] M. Esmaeili, P.Y. Mojir, "Substructure nonlinear effects on sleeper design pressure in heavy haul railway tracks", Journal of Transportation Engineering 137(9), 656-664, 2011.

[17] A.D. Kerr, "Fundamentals of Railway Track Engineering". SimmonsBoardman Books Incorporated, Omaha, Nebraska, 2003.

[18] D. Li, E.T. Selig, "Method for railroad track foundation design. II: Applications", Journal of Geotechnical and Geoenvironmental Engineering 124(4), 323-329, 1998.

[19] B. Lichtberger, "Track Compendium: Track System, Substructure, Maintenance, Economics”, DVV Media Group, Hamburg, 2011.

[20] C.C.J. Kwan, "Geogrid reinforcement of railway ballast", Doctoral dissertation, University of Nottingham, 2006.

[21] P.K. Woodward, et al, "Application of polyurethane geocomposites to help maintain track geometry for high-speed ballasted railway tracks", Journal of Zhejiang University SCIENCEA, 13(11), 836-849, 2012.

[22] H.-M. Chen, C. Ulianov, R.E. Shaltout, "A Holistic Design Approach using Advanced Computing Tools for Railway Track Modelling", in J. Kruis, Y. Tsompanakis, B.H.V. Topping, (Editors), "Proceedings of the Fifteenth International Conference on Civil, Structural and Environmental Engineering Computing", Civil-Comp Press, Stirlingshire, UK, Paper 197, 2015. doi:10.4203/ccp.108.197 